https://doi.org/10.46344/JBINO.2021.v10i2b.10

\title{
EVALUATION OF RADON CONCENTRATIONS IN GROUNDWATER OF THE SOUTHERN PART OF GAZA STRIP, PALESTINE
}

Samir Hararah', Zeyad Abu Heen', Samir Yassin², Samer Abuzerr 3

${ }^{I}$ Department of Earth and Environmental Science, Islamic University of Gaza, Gaza Strip, Palestine ${ }^{2}$ Department of Physics, Faculty of Sciences, Islamic University of Gaza, Gaza strip, Palestine

${ }^{3}$ Quality Improvement and Infection Control Unit, Ministry of Health, Gaza strip, Palestine

Email: samer_516@hotmail.com

\begin{abstract}
Background: This research's primary objective is to determine the Radon concentration in groundwater in the Gaza Strip's southern governorates. Materials and Methods: Groundwater samples were collected from twenty-five wells, and Radon concentrations were measured as part of water quality. These samples were taken from the municipal wells in the southern governorates of the Gaza Strip (Rafah and Khanyonis) of the Gaza strip. CR-39 solid-state nuclear track detectors of good quality were used in this survey. Two Detectors were placed inside each water sample. One CR-39 detector was immersed in the water, and the other is in the lid of the container facing the water sample. The detectors were left for 120 days (from April to the middle of August) to allow Radon gas to reach an equilibrium level. The detectors were then collected and chemically etched. Each detector was counted visually using an Optical microscope with a power of $(40 \times 10)$, and the number of tracks determined. Results: Findings showed that the Radon levels in the Rafah area ranged between 58 and $154 \mathrm{~Bq} / \mathrm{m}^{3}$ with an average value of $102.4 \mathrm{~Bq} / \mathrm{m}^{3}$. The average standard deviation (S.D.) is 32.7 and in Khanyonis area ranges of values between 22 and $132 \mathrm{~Bq} / \mathrm{m}^{3}$ with an average weight of $47.8 \mathrm{~Bq} / \mathrm{m}^{3}$, the average standard deviation of 31.9. This variation of levels is mainly due to the difference in rock type, soil type, and area's geology. Conclusion: More investigation and drawing maps for the radiation pollution in groundwater in the Gaza Strip is required.
\end{abstract}

Keywords: CR-39 Detectors, $\mathrm{Rn}^{222}$ concentration level, Groundwater, Exposure survey, Dosimeter, Gaza strip, Palestine 


\section{INTRODUCTION}

On a global scale, groundwater and surface water may contain many constituents, including microorganisms, gases, radioactive particles, inorganic and organic materials. Scientists assess water quality by measuring the various components included in the water (1).

Several environmental problems are seriously threatening Gaza Strip. Deterioration of groundwater quality is considered one of the main issues that exert massive pressure on our economics and need for an urgent response because it is not received severe investigation. Exposures to radioactive materials are one of these water quality problems that were not investigated widely and will focus on this study. Drinking water came from groundwater and is supplied through public drinking water systems. But many families rely on private, household wells and use groundwater as their source of freshwater. The quality of drinking water is affected by groundwater depth from the surface because there is a chance of being polluted varies from place to place. Human activities can alter groundwater's natural composition, causing an undesirable change in groundwater quality in the form of contamination or pollution. Groundwater may contain some natural impurities or contaminants, even with no human activity or pollution (2-5).

This study aims to investigate natural radiation pollution in groundwater of the southern part of Gaza Strip, depending on measurements of Radon concentration in selected wells in the area.
Groundwater is the primary source of water in the Gaza Strip. Most of the residents receive drinking water services and supplied by municipal wells after disinfecting water with chlorine. The groundwater is used for domestic, agricultural, and industrial purposes. Extensive pumping has caused severe quantitative and qualitative problems in the aquifer (4, 6-12).

Natural contaminants can come from many conditions in the watershed or the ground. Water moving through underground rocks and soils may pick up magnesium, calcium, and chlorides. Coastal areas and especially the southern part of the Mediterranean region faces many causes of unacceptable groundwater quality that related mainly to human activities (13)

Some groundwater naturally contains dissolved elements such as arsenic, boron, selenium, or Radon, a gas formed by the natural breakdown of radioactive uranium in the soil. Whether these biological contaminants are health problems depends on the amount of the substance present. The elements that produce radiation are called radioactive. Radon itself is radioactive because it also decays, losing an alpha particle and forming the element polonium (14).

The relationship between drinking water and indoor Radon concentration is an essential environmental radiology problem and perhaps underestimated. During domestic water use, as the water is heated and the Radon becomes less soluble, 
Radon from water is degassed into the indoor air (15).

Investigate the presence of natural radiation in groundwater in the Gaza Strip. It may be due to some radioactive minerals derived from the source rock along the coast of the country, where the most significant portion of the radiation exposure comes from naturally occurring radiation sources such as Radon. Therefore, the radioactive pollution monitoring system in groundwater should be investigated because no clear cut research has been done in the past (16).

Despite the usual safety measures in and around the reactors in the adjacent countries of the Gaza Strip, there is always a danger of radiation leakage. We believe that nuclear waste stored in Israel may affect the environment in the Gaza Strip, which raises water pollution. Therefore, the study of radiation pollution in groundwater is remarkably recommended.

Most of the studies carried out on the quantitative and qualitative in the water resources in Gaza Strip. However, less attention has been given to determine the radionuclide in water. Radon in water is responsible for the whole body's internal radiation dose that may be more harmful than Radon in air. Thus, Radon's determination in groundwater has also been of significant interest because of its detrimental health, which causes lung cancer.

\section{MATERIALS AND METHODS}

The water samples were collected from the collected water sources in each city in the Gaza Strip's southern part. Twenty-five groundwater Samples were collected from the municipal wells in the Southern part of the Gaza Strip. Some of these wells have lithological descriptions. Some information comes from the geologists, who obtain their information from boreholes and geophysical prospecting; geophysical welllogging in the boreholes gives additional geophysical details (6). One liter of each sample was placed in a plastic jar. The samples were collected from different locations, 12 wells from Rafah Governorate, and 13 wells from Khanyonis Governorate. Al these wells are used for domestic water (Figure 1 and Figure 2).

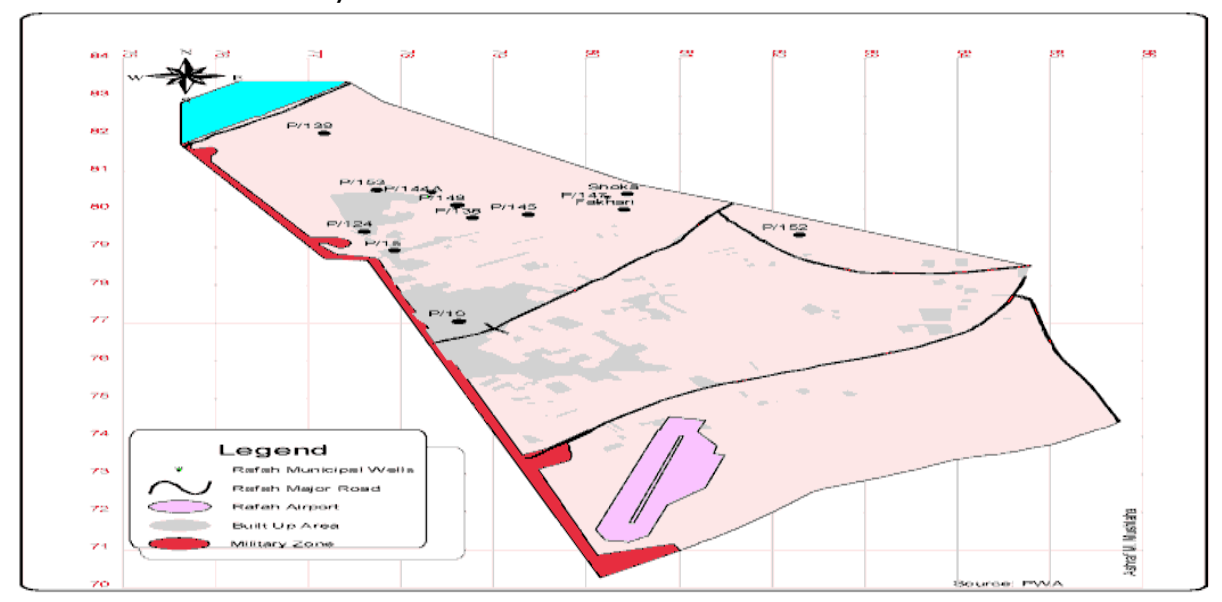


Figure 1. Wells location of the samples for Rafah Governorate.

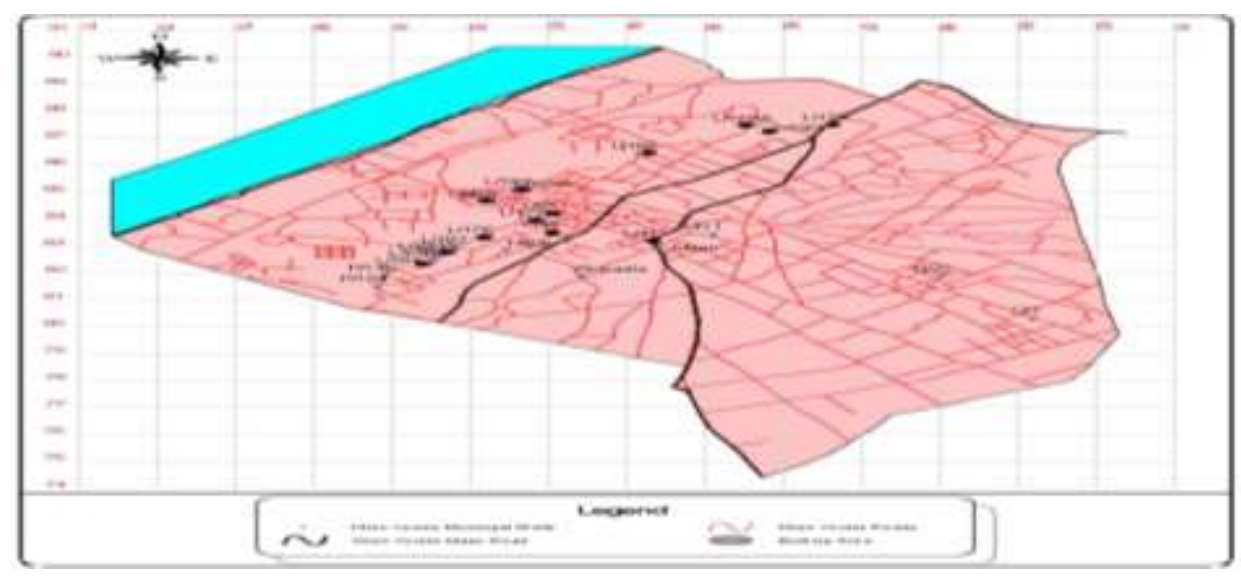

Figure 2. Wells location of Samples for Khanyonis Governorate.

Each sample was duplicated to determine Radon concentration. The water samples were taken after five minutes from operating the wells, and we put the samples in a plastic container, where information data for each well such as well name, well number, site, data of collection sample, and exposure period is registered in a form fixed on Jar. A questionnaire is also accompanied by the collection sample, including questions regarding the collection site, time, and factors necessary for analysis. Two detectors were also fixed inside a plastic container (Jar), as shown in figure 3. One of these detectors was placed at the plastic cover (lid), and the box was tightly sealed. The detectors were left for a total exposure of 120 days (for a period from April to the middle of August). Software surfer eight and Excel programs are used for the analysis of results.

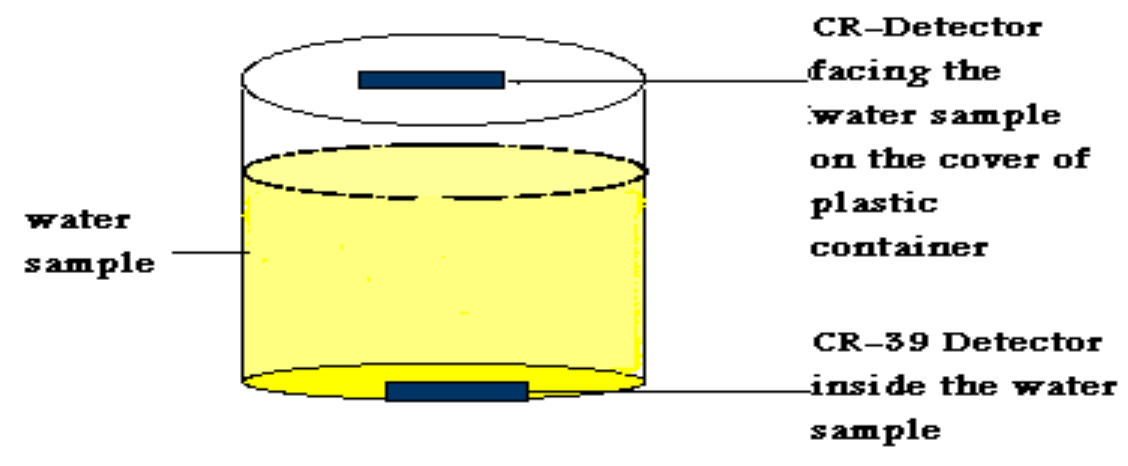

Figure 3. The two detectors in water samples

\section{RESULTS AND DISCUSSION}

We have analyzed the collected detectors CR-39 and No. of tracks are determined. The Radon level concentration in Rafah and Khanyonis governorates is measured in $\mathrm{Bq} / \mathrm{m}^{3}$. The results obtained are listed below and explained. 
Figure 5 shows Radon Concentration for each water sample in the Rafah governorate. The results indicate that the difference between the minimum $58 \mathrm{~Bq} / \mathrm{m}^{3}$ and the maximum value of $154 \mathrm{~Bq} / \mathrm{m}^{3}$.of the Radon concentrations for each well in the governorate is very high. This considerable variation in Radon concentrations may be mainly due to the difference in the soil type, rock type, and depth of these wells, this clear in wells with numbers $(P / 138, P / 152, P / 148$, and $P / 153)$ that have high clay. Some locations in Rafah governorate that have low-level Radon are considered to be rural and farm territories. This is probably due to the little content of clay rocks, which contain Radon's primary source in the surveyed area.

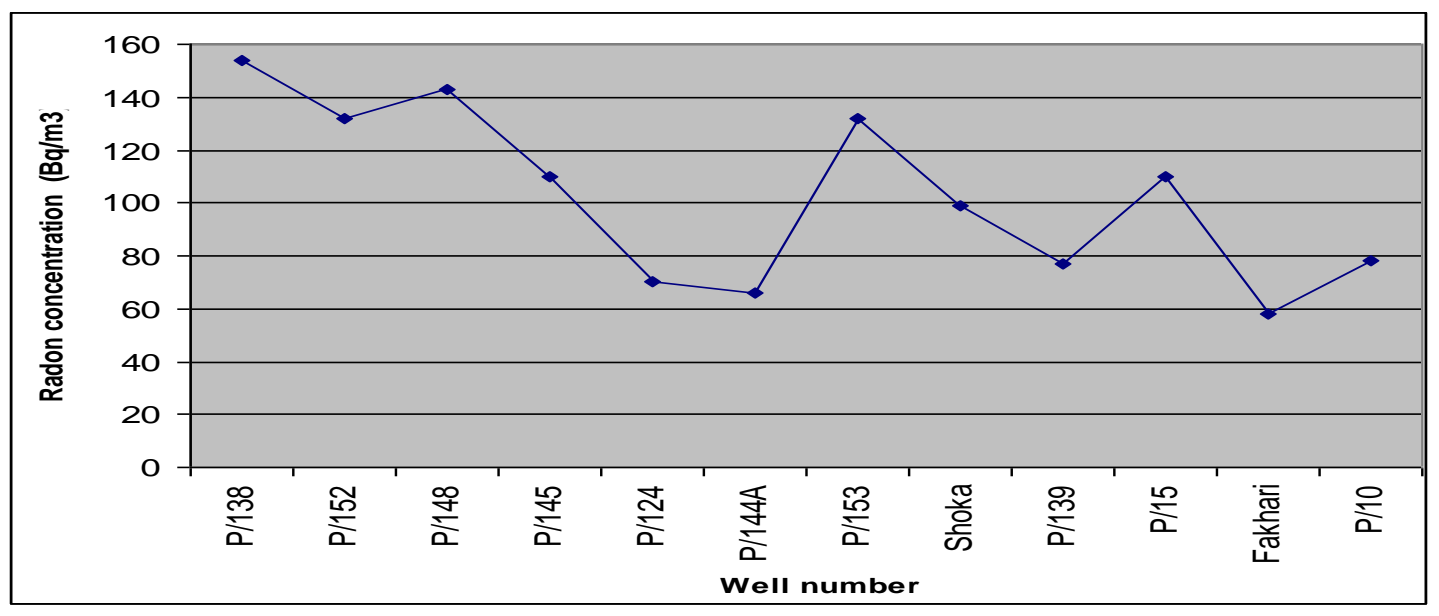

Figure 5. Radon concentration for each water sample in Rafah Governorate.

The Radon concentration in each water sample in Khanyonis Governorate for different locations measured in $\mathrm{Bq} / \mathrm{m}^{3}$ is shown in figure 6 . The arithmetic mean of measurements was $47.8 \mathrm{~Bq} / \mathrm{m}^{3}$ with a range of values between 22 and 132 $\mathrm{Bq} / \mathrm{m}^{3}$ and an average standard deviation of 31.9. The results indicate that the difference between the minimum and maximum Radon concentrations in the governorate is also very high and even higher than in Rafah. This considerable variation in Radon concentrations may be due mainly to the difference in the soil type, rock type, and depth of these wells. 


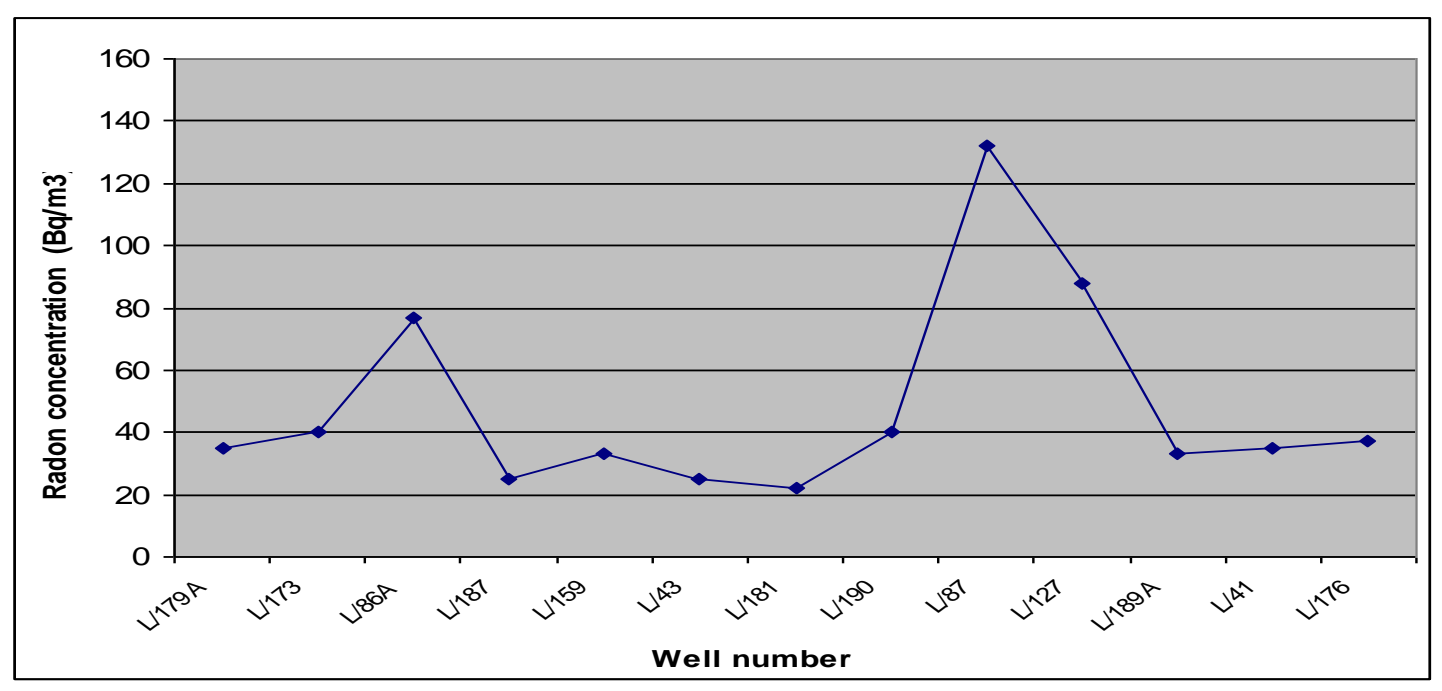

Figure 6. Radon concentration for each water sample in Khanyonis Governorate.

Most wells show a low level of Radon concentration in Khanyonis governorate because of little clay; meanwhile, other wells give a high level of Radon, and these trends may be due to the soil types, lithology (high clay), and the depth of the wells. Table 1 illustrates the numbers of collected detectors from water samples, the minimum and maximum concentrations of Radon in the Southern Governorate. The average Radon concentrations (C) and the standard deviation (S.D.) for each governorate in the survey location are also shown in table 1.

Table 1. Radon concentrations in each Governorate and S. D.

\begin{tabular}{|c|c|c|c|c|c|}
\hline $\begin{array}{c}\text { The } \\
\text { Region }\end{array}$ & $\begin{array}{c}\text { No.of } \\
\text { detectors }\end{array}$ & $\begin{array}{c}\text { Ave. } \\
\mathbf{C}\left(\mathbf{B q} / \mathbf{m}^{\mathbf{3}}\right)\end{array}$ & $\begin{array}{c}\text { Max. } \\
\mathbf{C}\left(\mathbf{B q} / \mathbf{m}^{\mathbf{3}}\right)\end{array}$ & $\begin{array}{c}\text { Min. } \\
\mathbf{C}\left(\mathbf{B q} / \mathbf{m}^{\mathbf{3}}\right)\end{array}$ & S.D. \\
\hline Rafah & 48 & 102.4 & 154 & 58 & 32.7 \\
\hline Kanyon is & 52 & 47.8 & 132 & 22 & 31.9 \\
\hline Average & - & 75.1 & 143 & 40 & 32.3 \\
\hline
\end{tabular}

The Radon levels ranges of values between 58 and $154 \mathrm{~Bq} / \mathrm{m}^{3}$ with an average value of $102.4 \mathrm{~Bq} / \mathrm{m}^{3}$ are also obtained, and the average standard deviation is $32.7 \mathrm{~Bq} / \mathrm{m}^{3}$. We believe that this variation of levels is mainly due to the difference in rock type, soil type, and area's geology. However, the layers in wells No. (P/152), (P/148), (P153), $(P / 138)$ in Rafah Governorate is salty clay and pure clay. These layers are considered source as natural radioactive, and in well No L/43, which has a low concentration level in Khanyonis governorate, has a small layer of clay, as shown in figure 7. This estimation is relatively close to that of the international commission on radiological protection (ICRP). However, this study should be followed by additional works 
covering other wells in the study region to Radon concentration in the Gaza Strip. get comprehensive information about

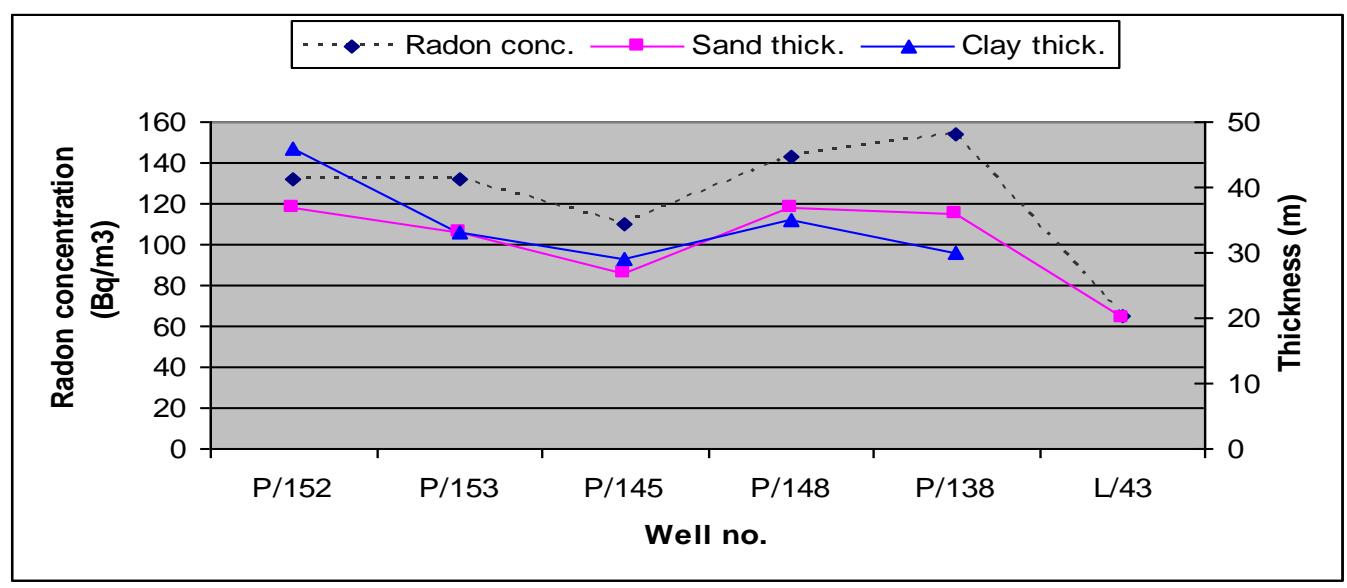

Figure 7. The relation between Radon concentration and Layers thicknesses and types in the study area The relation between Radon concentration and both sand and clay thicknesses is illustrated in figure 7 . It is well shown that good relations could be achieved. The figure shows both sand and clay thicknesses are in a good correlation with Radon concentration. Radon concentration increases as sand and clay increase.

\section{Interpretation of contouring map of Radon concentrations}

To understand the spatial variation of Radon concentration for 25 water well samples, the geographic location ( $X$ and $Y$ ) of each well used to draw a contouring map for the investigated areas, and the corresponding measured Radon concentration for the well. The SURFER Software program is used to draw the contour map of the data obtained from the study area, and the results are illustrated in figure 8.

Figure 8 shows that Radon concentrations increase in two directions; the first is from North to South - and the other from west to east. The map also shows that three large anomalies were well observed. The first one is located in the northeast of Khanyonis city, where the two others are in the southwest of Rafah. However, a more and extensive survey is needed to ensure and explain these anomalies so that we can identify the factors that affect Radon concentrations in the study area. 


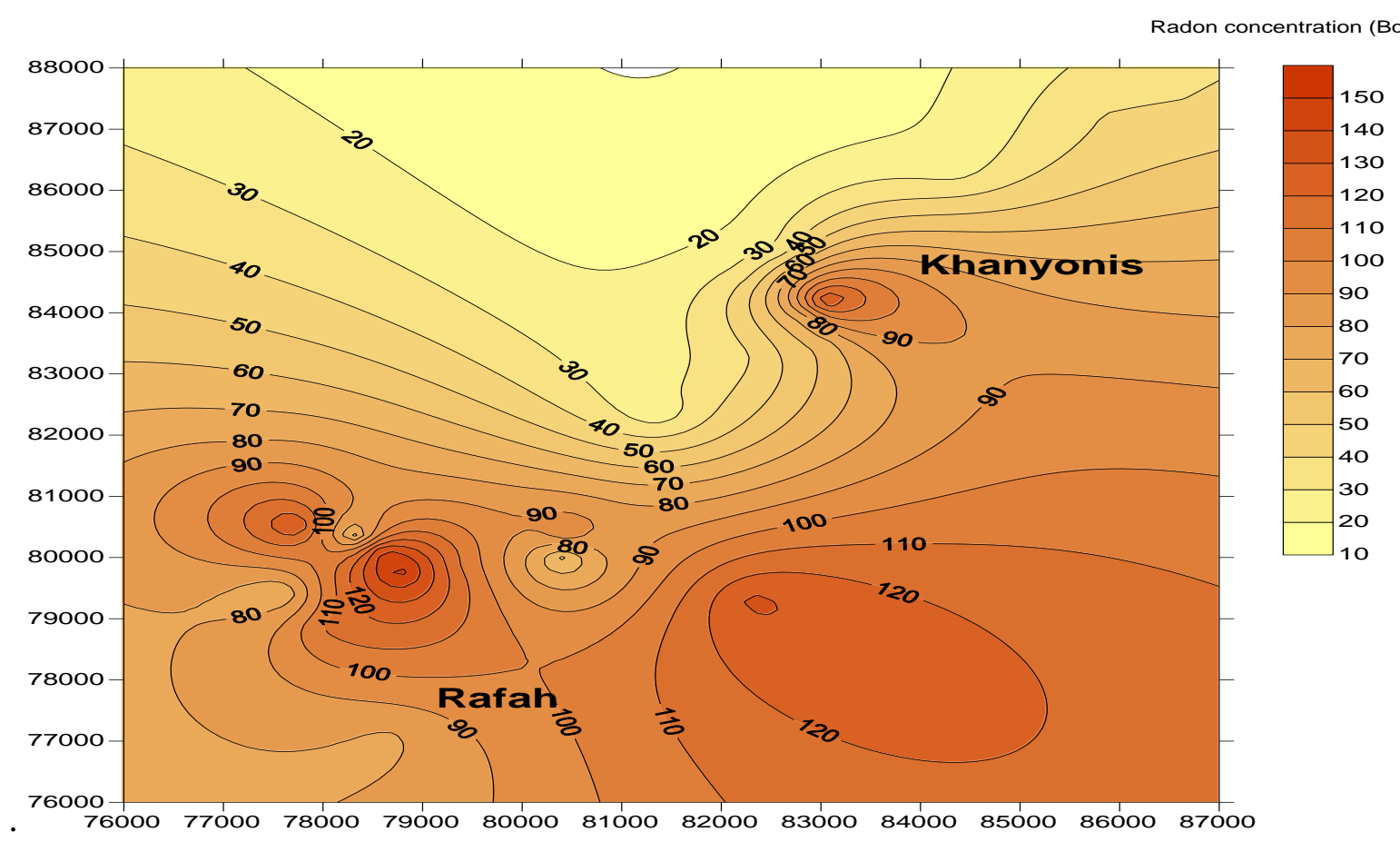

Figure 8. Contour map of Radon concentration for the study area

It is believed that the increase of Radon concentrations in the direction mentioned above is related to soil types. In general, we found that Radon's concentration ranges from $\left(22\right.$ - up $\left.154 \mathrm{~Bq} / \mathrm{m}^{3}\right)$ in Khanyonis and Rafah governorates. There is also a remarkable increase in Radon concentration in the wells that lie on the western south of Rafah and the well L/87 in the Khanyonis area. This increase in attention is due to soil type (sandy clay soil and salty clay or pure clay). The lithology, soil types, and depth of the well consists of a clay layer of heavy thickness, where the clay is known as the radiation source.

Despite the safety measures taken into consideration of nuclear reactors and nuclear institutions found in adjacent countries, we believe that there is always radiation from the cross border. Remarkably, the effect of the Israeli atomic reactor (Demona reactor) in the Naqab area. So far, there is no clear cut evidence to point out this leakage of radiation. This is due to the lack of nuclear equipment and detectors available in the country. However, most of the previous studies dictated an increase in lung cancer diseases and infant fatal in Gaza Strip (17). Although the work in this field is not initially meant for a national project, yet these pits and lots constitute together:

1) A basis for a nationwide characterization of Palestine in terms of Radon concentration.

2) An acceptable database for risk estimations from such radiation of water pollutants.

To remedy the harmful radiation effects of water pollutants, many factors should be taken into consideration. These include the nature of the source of exposure, the type of radiation released from those sources, 
the nature of the well and soil type, and social and economic consideration as this type of work depends mostly on the developing database of the environmental radioactivity and radiation dosimetry. Thus, efforts need to be concentrated not only on specified sites of interest but also on other potential situations and factors. To give a relatively comprehensive vision, a contribution from human-made radiation sources is also required to provide the annual useful dose values. Radon's contribution (222Rn) in domestic water supplies has been investigated and found to be significant for concentration over a few hundred Becquerel per cubic meter in the water supply.

Measurements have also revealed a relationship between the Radon levels and depth of wells. Figure 9 displays the Radon concentrations with the peak of wells measured in Rafah city. These values give the relationship between the depth of wells that range (56-102m) and Radon levels (58$\left.154 \mathrm{~Bq} / \mathrm{m}^{3}\right)$.

The data about the location of the drilled well, site-specific well and well information such as well discharge rate and well depth. All these data of the wells can be found in the Palestinian Water Authority (6). Figure 9 illustrates the Radon concentration with the depth of wells. As can be deduced, the wells with high Radon values are located on high peaks, and wells with lower Radon values are comparatively on low depth. Although the conclusion is not that obvious for the relative attitude with the wells' depth, the Radon concentration can be observed at different depth levels. The measured values for Khanyonis city for useful depths are also obtained and give similar trends of a significant relationship. This estimate is relatively close to that described by demsar skeppstorm, 2005, who found an association between Radon concentrations in water with wells' depth. The study was carried out in the central part of Stockholm country, where 293 drill wells located in that area have been subject to investigation. However, this study can also be deduced that Radon's higher values correspond to regions with either sand or clay.

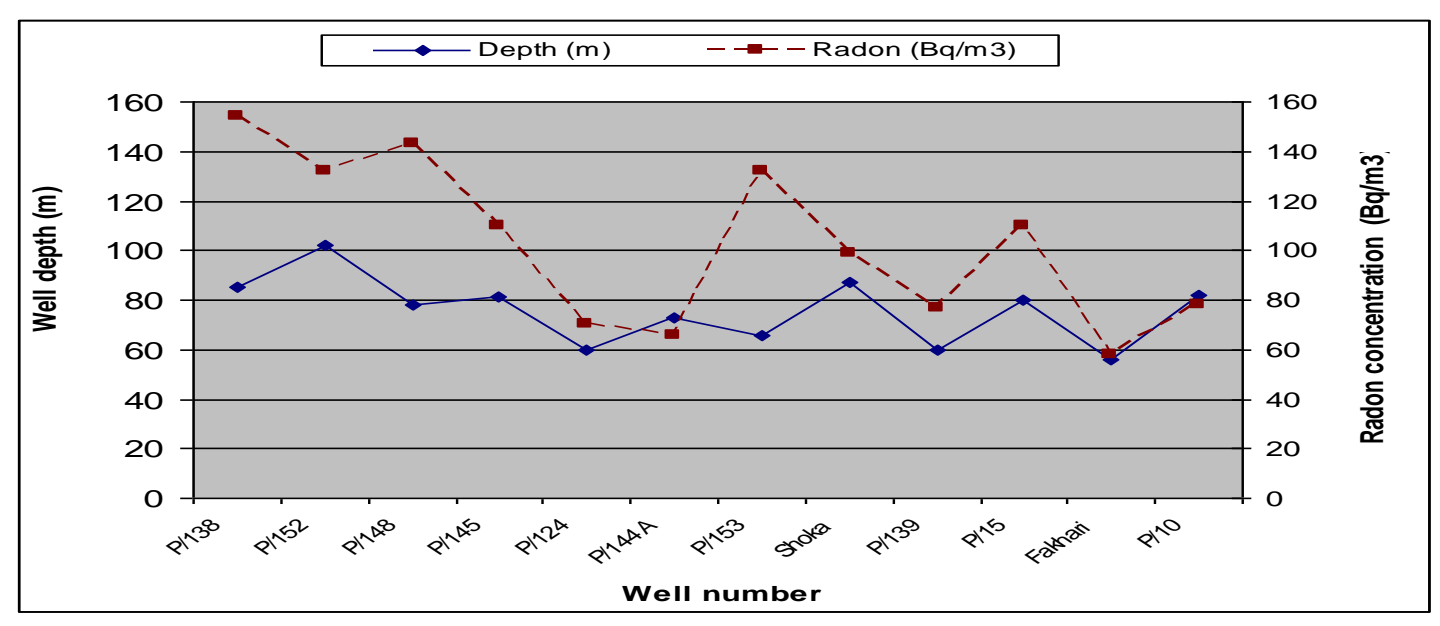


Figure 9. The relationship between Radon concentration and wells depth in Rafah Governorate

Figure 10 displays the Radon concentrations with the depth of wells measured in Khanyonis governorate. These Values give the relationship between the height of wells that ranges $(23-61 \mathrm{~m})$ and
Radon levels $\left(22-132 \mathrm{~Bq} / \mathrm{m}^{3}\right)$. As can be deduced, the wells with high Radon values are located on high depths, and wells with lower Radon values are comparatively on low height.

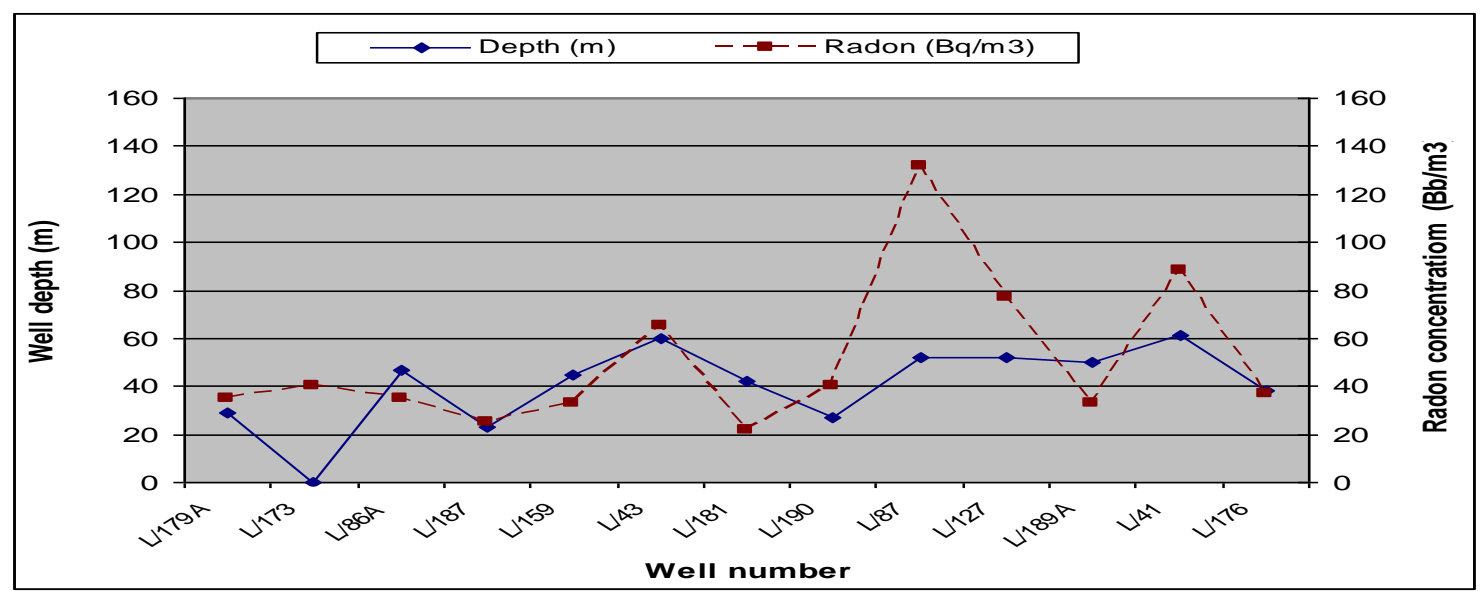

Figure 10. The relationship between Radon concentration and wells depth in Khanyonis Governorate.

\section{Conclusions}

Air, soil, and water pollution are believed to be responsible for many diseases spread in Gaza Strip. Radon gas presents universally indifferent air, soil, and water concentrations that negatively impact public health and cause lung cancer. This study focus on measuring the Radon levels in groundwater in the southern governorates of the Gaza Strip. Different factors that affected Radon concentration were also investigated. Radon produced in the soil matrix can quickly diffuse to the water trapped in the pore spaces and migrate to groundwater. Radon and its short-lived daughter products represent the primary source of exposure to natural radiation. Radon is now believed to be the most crucial source of ionizing radiation in our environment. Results obtained show that the Radon levels in Rafah range from 58 and $154 \mathrm{~Bq} / \mathrm{m}^{3}$ with an average value of $102.4 \mathrm{~Bq} / \mathrm{m}^{3}$, and the standard deviation (S.D.) is 32.7. Also, in the Khanyonis area, Radon levels range of values between 22 and $132 \mathrm{~Bq} / \mathrm{m}^{3}$ with an average weight of $47.8 \mathrm{~Bq} / \mathrm{m}^{3}$ and a standard deviation (S.D.) of 31.9. The variation of levels could be mainly due to the difference in rock type, soil type, and depth of the well, and the area's geology. The relation of Radon concentration with other factors is also investigated in the present work concerning wells' center. The results show that the wells with high Radon values were noticed to be located on high depth, and lower Radon values are comparatively on low center. The results typically provide 
preliminary reconnaissance coverage of Radon concentration in groundwater. However, a radiometric survey under certain conditions can be used for geologic mapping. The area surveyed was selected based on geological, topographical consideration, and other preliminary studies. This fact is related to the soil (sand and clay) being the primary source of Radon, where we suspect that industrial nuclear waste is buried in that area.

Conflicts of interest: The authors declare that they have no conflicts of interest.

\section{References}

1. Hem JD. Study and interpret the chemical characteristics of natural water: Department of the Interior, U.S. Geological Survey; 1985.

2. Abuzerr S, Hadi M, Zinszer K, Nasseri S, Yunesian $M$, Mahvi AH, et al. Comprehensive Risk Assessment of HealthRelated Hazardous Events in the Drinking Water Supply System from Source to Tap in Gaza Strip, Palestine. Journal of Environmental and Public Health. 2020;2020.

3. Abuzerr $S$, Nasseri $S$, Yunesian $M$, Hadi $M$, Zinszer $K$, Mahvi AH, et al. water, sanitation, and hygiene risk factors of acute diarrhea under-five children in the Gaza Strip. Journal of Water, Sanitation, and Hygiene for Development. 2019.

4. Abuzerr $S$, Nasseri $S$, Yunesian $M$, Hadi $M$, Mahvi AH, Nabizadeh $R$, et al. Household drinking water safety among the Gaza Strip population, Palestine: knowledge, attitudes, practices, and satisfaction. Journal of Water, Sanitation, and Hygiene for Development. 2019;9(3):500-12.

5. Abuzerr $S$, Nasseri $S$, Yunesian $M$, Yassin S, Hadi $M$, Mahvi $A H$, et al. Microbiological quality of drinking water and prevalence of waterborne diseases in the Gaza strip, Palestine: a narrative review. Journal of Geoscience and Environment Protection. 2019;7(04):122.

6. PWA. Coastal Aquifer Management Program (CAMP), Integrated Aquifer management Plain(task-3)Appendix a. Palestinian Water Authority, Gaza, Palestine. 2000; The radon Information Centre "The Radon facts sheet" (www.Radon.com/Radon/Radon_facts.ht $\mathrm{ml}, 1999)$.

7. Abuzerr $S$, Nasseri $S$, Yunesian $M$, Hadi $M$, Mahvi AH, Nabizadeh $R$, et al. Prevalence of diarrheal illness and healthcare-seeking behavior by agegroup and sex among the population of Gaza strip: a community-based crosssectional study. BMC public health. 2019;19(1):704.

8. AlKhaldi M. AS, Obaid H.A., Alnajjar G., Alkhaldi A., Alkaiyat A. Social Determinants of Health in Fragile and Conflict Settings: The Case of the Gaza Strip, Palestine. In: Laher I (eds) Handbook of Healthcare in the Arab World Springer, Cham https://doiorg/101007/978-3-31974365-3 203-1. 2020.

9. HEEN, Zeyad H. Abu; MUHSEN, Shehda A. Electrical resistivity tomography for coastal sea water intrusion characterization along Rafah Area, South 
of Gaza Strip, Palestine. IUG Journal of Natural Studies, 2017.

10. Abu Heen, Z. H., \& Muhsen, S. A. (2017). Estimation of Aquifer Parameters from Vertical Electrical Sounding Measurements South Gaza Strip, Palestine. In IUG Journal of Natural Studies:(Special Issue) The Sixth International Conference on Science \& Development 14-15 march 2017 (Vol. 25, No. 2).

11. HEEN, Zeyad Hassan Abu; MUHSEN, Shehda. Application of vertical electrical sounding for delineation of sea water intrusion into the freshwater aquifer of southern governorates of Gaza Strip, Palestine. IUG Journal of Natural Studies, 2016, 24.2.

12. El-Naeem, M. F. A., Heen, Z. A., \& Tubail, K. (2009). Factors behind Groundwater Pollution by Nitrate in North Governorates of Gaza Strip (1994-2004). In Thirteenth International Water Technology Conference, IWTC (Vol. 13, p. 2009).

13. Almahallawi K. Modelling interaction of land use, urbanization, and hydrological factors to analyze groundwater quality in Mediterranean zone (example the Gaza Strip, Palestine): Lille 1; 2005.

14. Ayotte JD, Gronberg JM, Apodaca LE. Trace elements and Radon in groundwater across the United States, 1992-2003: U.S. Department of the Interior, U.S. Geological Survey; 2011.

15. Edition F. Guidelines for drinkingwater quality. WHO chronicle. $2011 ; 38(4): 104-8$.
16. Yassin S, Al Sersawi $M$, Abuzerr $S$, Darwish $M$. Indoor radon levels in the dwellings of the Gaza governorate neighborhoods', Palestine. International Journal of Radiation Research. 2019;17(4):541-8.

17. $\mathrm{MOH}$. Annual report, the status of health in Palestine. Ministry of Health. 2002;http://www.moh.gov.ps/portal/en/. 